OPEN ACCESS

Edited by:

Takashi Osanai,

Meiji University, Japan

Reviewed by:

Weiwen Zhang

Tianjin University, China

Wendy Schluchter,

University of New Orleans, USA

${ }^{*}$ Correspondence:

Qingfang He

qfhe@ualr.edu

Specialty section:

This article was submitted to Microbiotechnology, Ecotoxicology and Bioremediation,

a section of the journa

Frontiers in Microbiology

Received: 10 November 2015 Accepted: 09 December 2015

Published: 24 December 2015

Citation:

Ranade S, Zhang Y, Kaplan M, Majeed W and $H e$ Q (2015) Metabolic

Engineering and Comparative Performance Studies

of Synechocystis sp. PCC 6803

Strains for Effective Utilization of Xylose. Front. Microbiol. 6:1484. doi: 10.3389/fmicb.2015.01484

\section{Metabolic Engineering and Comparative Performance Studies of Synechocystis sp. PCC 6803 Strains for Effective Utilization of Xylose}

\author{
Saurabh Ranade', Yan Zhang'2, Mecit Kaplan', Waqar Majeed ${ }^{3}$ and Qingfang He ${ }^{\text {* }}$ \\ ' Department of Biology, University of Arkansas at Little Rock, Little Rock, AR, USA, ${ }^{2}$ Biotechnology Research Center, \\ Shandong Academy of Agricultural Sciences, Jinan, China, ${ }^{3}$ Center for Integrative Nanotechnology Sciences, University of \\ Arkansas at Little Rock, Little Rock, AR, USA
}

Wood sugars such as xylose can be used as an inexpensive carbon source for biotechnological applications. The model cyanobacterium Synechocystis sp. PCC 6803 lacks the ability to catabolize wood sugars as an energy source. Here, we generated four Synechocystis strains that heterologously expressed XyIAB enzymes, which mediate xylose catabolism, either in combination with or without one of three xylose transporters, namely XyIE, GalP, or Glf. Except for glf, which is derived from the bacterium Zymomonas mobilis ZM4, the heterologous genes were sourced from Escherichia coli K-12. All of the recombinant strains were able to utilize xylose in the absence of catabolite repression. When xylose was the lone source of organic carbon, strains possessing the XyIE and Glf transporters were most efficient in terms of dry biomass production and xylose consumption and the strain lacking a heterologous transporter was the least efficient. However, in the presence of a xylose-glucose mixed sugar source, the strains exhibited similar levels of growth and xylose consumption. This study demonstrates that various bacterial xylose transporters can boost xylose catabolism in transgenic Synechocystis strains, and paves the way for the sustainable production of bio-compounds and green fuels from lignocellulosic biomass.

Keywords: cyanobacteria, metabolic engineering, mixotrophy, LAHG, Synechocystis, xylose transporter

\section{INTRODUCTION}

Lignocellulosic material is an abundant, inexpensive, and renewable source of carbon with potential industrial applications (Ragauskas et al., 2006). Large quantities of lignocellulosic biomass are generated in agricultural, forestry, and related industries each year. This residual biomass can be used to synthesize a number of value-added products (Pothiraj et al., 2006), especially energy-rich compounds that can be used as biofuels (Ragauskas et al., 2006; Lee and Lavoie, 2013; Anwar et al., 2014). Lignocellulose is typically composed of cellulose (40-50\%), hemicellulose (20-30\%), and lignin (10-15\%) macromolecules bound together by hydrogen and covalent bonds (Malherbe and Cloete, 2002; Kumar et al., 2009). Hydrolysis of lignocellulose yields xylose, which is the second most abundant sugar in the biosphere after glucose. Xylose accounts for up to 35\% of the total dry weight (DW) of plant materials (Gìrio et al., 2010). Catabolism of D-xylose begins with its transport into the cell by means of specific transporter proteins. Once inside the cell, xylose is isomerized by 
$\mathrm{D}$-xylose isomerase (XylA) to yield D-xylulose, which in turn is irreversibly phosphorylated by the action of xylulokinase (XylB) to yield D-xylulose 5-phosphate, a pentose phosphate pathway (PPP) intermediate (Figure 1) (Doelle, 1975).

Few microorganisms are able to catabolize pentose sugars (Jojima et al., 2010). Even in pentose utilizing microorganisms, factors that impair pentose catabolism exist, such as catabolite repression (Vinuselvi et al., 2012), cellular redox imbalance, and insufficient transporter activities (Matsushika et al., 2009). Hence, effective utilization of pentose sugars by microorganisms requires the expression of heterologous genes (Jojima et al., 2010).

Although primarily photoautotrophic, a number of cyanobacteria can utilize organic carbon compounds (Eiler, 2006). In large-scale cyanobacterial cultures, mixotrophic growth conditions increase biomass production, whereas light and $\mathrm{CO}_{2}$ limit cyanobacterial growth and biosynthesis (Yao et al., 2014). Their unicellular nature, ability to photosynthesize and fix carbon dioxide, and amenability to genetic modification make cyanobacteria promising host organisms for biotechnological applications (Lu, 2010).

Several groups have introduced heterologous xylose transporter and/or metabolic genes into bacterial strains either to impart or improve the ability to transport and/or catabolize xylose. In an early study, the xylose catabolic genes $x y l A B$ and PPP genes talB-tktA from Escherichia coli were successfully expressed with the help of the GAP and ENO promoters, respectively, in Zymomonas mobilis CP4 to obtain a co-fermenting strain (Zhang et al., 1995). Similarly, the E. coli $x y l A B$ genes were successfully expressed under the $t r c$ promoter in the bacterium Corynebacterium glutamicum $\mathrm{R}$ to generate a diauxically growing strain (Kawaguchi et al., 2006), and also under the tac promoter in Pseudomonas putida S12. A laboratory evolution approach was used to generate a $P$. putida S12 strain with an increased biomass yield. The strain, however, failed to overcome diauxic growth. Introduction of the transporter genes $x y l F G H$ under the tac promoter failed to improve xylose metabolism, indicating that transport was not the limiting factor (Meijnen et al., 2008). xylAB genes from Streptomyces lividans TK23, when expressed under the tac promoter in the actinobacteria Rhodococcus opacus PD630 and Rhodococcus jostii RHA1, yielded efficient co-fermenting strains (Xiong et al., 2012). Heterologous expression of the Glf transporter from $Z$. mobilis CP4, which had been modified by error-prone PCR and random deletion/ligation, improved xylose transport in E. coli BL21 (Ren et al., 2009). One of the first reported attempts to engineer a cyanobacterium that could metabolize xylose involved

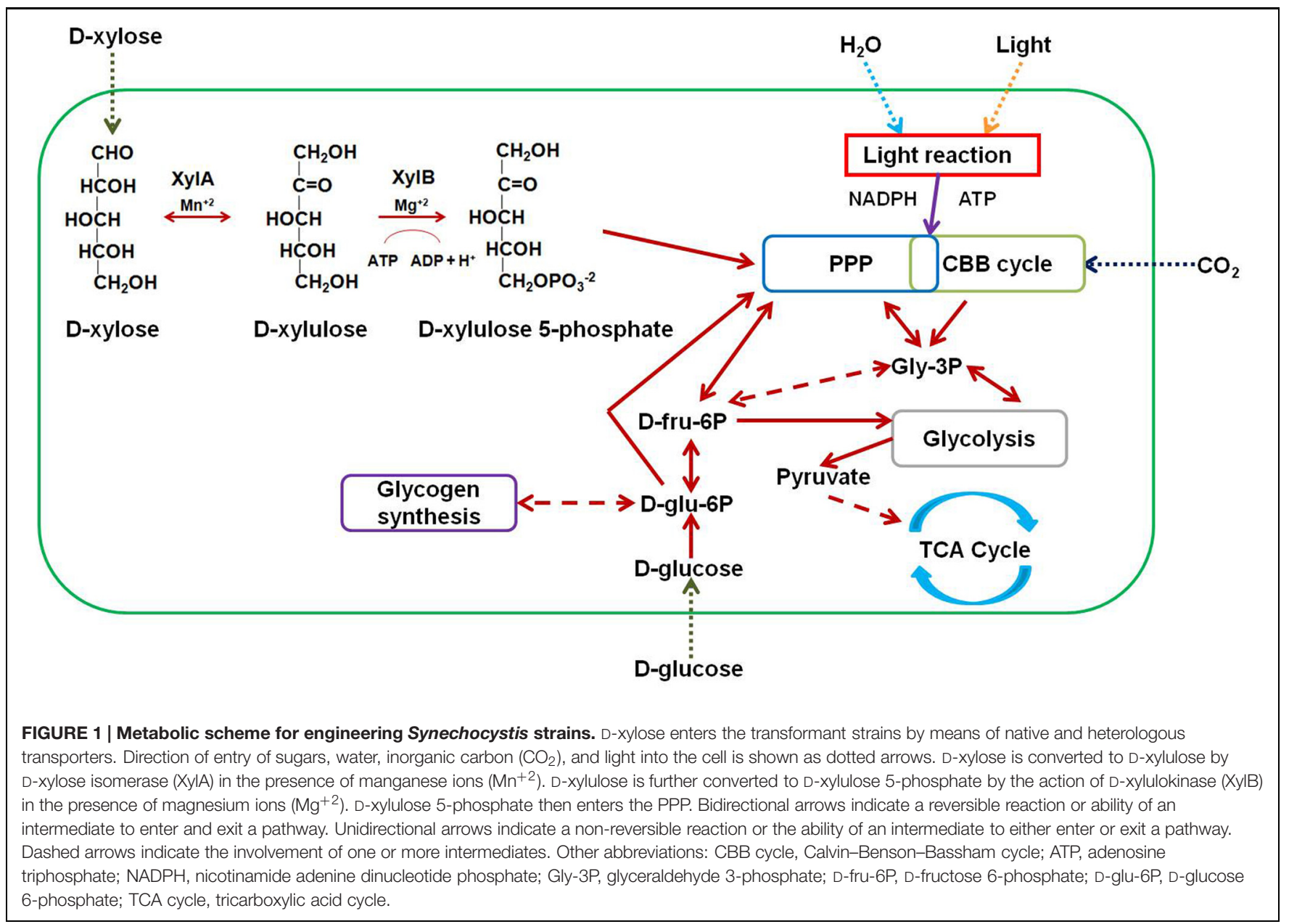


Synechococcus elongatus PCC 7942. The wild-type strain appears to catabolize xylose slowly. Expression of the E. coli $x y l E$ transporter gene under the control of the trc promoter impaired growth due to the intracellular accumulation of xylose. However, introduction of the $x y l E A B$ operon from the same source organism under the control of the $t r c$ promoter doubled growth in the presence of xylose (McEwen et al., 2013). In another study, expression of the E. coli $x y l A B$ genes under the $p s b A$ promoter increased the rate of ethylene production in the presence of xylose. Furthermore, expression of the E. coli $x y l A B$ genes in a glycogen synthase mutant enhanced the synthesis of keto acids. Introduction of the E. coli XylFGH transporter enhanced xylose utilization only at concentrations of above $10 \mathrm{mM}$ (Lee et al., 2015). In addition to bacteria, several yeast strains have been engineered for effective catabolism of xylose, with strategies ranging from expression of heterologous transporter-catabolic genes from bacteria and other fungi, to random mutagenesisevolutionary engineering of the recombinant strains (Young et al., 2010).

In this study, we compared the biomass yield and xylose uptake of four recombinant Synechocystis sp. PCC 6803 (hereafter Synechocystis) strains heterologously expressing xylose-specific catabolic genes $x y l A B$ without or with one of three known xylose transporters (XylE, GalP, Glf). XylE (proton symporter), GalP (proton symporter), and Glf (uniporter) are members of the Major Facilitator Superfamily (hereafter MFS) class of transporter proteins (Jojima et al., 2010). The glf transporter gene is native to Z. mobilis ZM4, whereas the other heterologous genes used in this study were sourced from E. coli K-12. Here we report the production of recombinant Synechocystis strains with various abilities to utilize xylose in the absence of catabolite repression. We show that the ability of Synechocystis to utilize organic carbon sources can be enhanced by the heterologous expression of efficient transporters.

\section{MATERIALS AND METHODS}

\section{Bacterial Strains and Growth Conditions}

Escherichia coli strain K-12 was used as a source organism for the amplification of xylose-specific transporter and catabolic genes. E. coli XL1-Blue (Stratagene) and TOP10 (Thermo Fisher Scientific) were used for DNA cloning and plasmid construction. The strains were grown at $37^{\circ} \mathrm{C}$ on solid LB medium or in liquid LB medium with shaking $(220 \mathrm{rpm})$ in the presence of an appropriate antibiotic, if needed. Antibiotic concentrations used for selection were as follows: ampicillin (Fisher Scientific), $100 \mu \mathrm{g} / \mathrm{ml}$ for liquid and solid media; kanamycin (Fisher Scientific), $25 \mu \mathrm{g} / \mathrm{ml}$ for liquid and solid media; and spectinomycin (Fisher Scientific), $25 \mu \mathrm{g} / \mathrm{ml}$ for liquid medium and $50 \mu \mathrm{g} / \mathrm{ml}$ for solid medium.

Zymomonas mobilis ZM4 was used as a source organism for amplification of xylose transporter-specific gene. The strain was grown at $28^{\circ} \mathrm{C}$ on solid YP medium or in liquid YP medium ( $1 \%$ yeast extract, $2 \%$ Bacto-peptone) with shaking (220 rpm).

\section{Plasmid Construction}

To construct the plasmids designed to insert xylose transporter genes into Synechocystis sp. PCC 6803, the kanamycin resistance cassette was spliced out from plasmid pUC4K (Vieira and Messing, 1982) using BamHI and inserted into pBluescript II $\mathrm{SK}+$ (Stratagene) digested with BamHI. The neutral site sequence (near slr1285; hereafter referred to as neutral site 1) (Xue et al., 2014b) was amplified from genomic DNA isolated from Synechocystis as upstream and downstream regions using the following primers:

5'-ACTCGGTACCGGCAATGCAATTAATTAAAAATGG-3' (forward primer) and $5^{\prime}$-ACTCCTCGAGTCTATTGTTGGAA GGTTGCTG-3' (reverse primer) for the upstream region; and $5^{\prime}$ ACTCACTAGTGTGAAAAAATATTGACATTAAGATATC-3'

(forward primer) and 5'-ACTCCCGCGGGGAACCAGATTTT TAGGATG-3' (reverse primer) for the downstream region. The upstream and downstream fragments were inserted between the KpnI-XhoI sites and SpeI-SacII sites of the modified pBluescript $\mathrm{SK}+$ plasmid, respectively. Next, a $\sim 0.4$-kb region encompassing the $p s b A 2$ promoter (hereafter $p s b A 2$ promoter) was amplified from Synechocystis genomic DNA using the following primers:

5'-ACTCGTCGACGGTATATGGATCATAATTGTATGC-

$3^{\prime}$ (forward primer) and 5'-ACTCGAATTCTTGGTTATAA TTCCTTATGTATTTGTC-3' (reverse primer). The amplified fragment was inserted between the SalI-EcoRI sites of the plasmid. Then, the $\sim 0.5-\mathrm{kb} 5 \mathrm{ST} 1 \mathrm{~T} 2$ double terminator region was amplified from the pBTac-1 plasmid (Boehringer Mannheim) using the following primers:

5'-ACTCCTGCAGCCAAGCTTGGCTGTTTTGG-3' (forward primer) and 5'-ACTCGGATCCATTGAAGCATTTAT CAGGGTTATTG-3' (reverse primer). The fragment was inserted between the PstI-BamHI sites of the modified pBluescript II SK+ plasmid. Finally, the xylose transporter genes, $x y l E$, galP, and $g l f$, were amplified from genomic DNA isolated from E. coli K-12 ( $x y l E$, galP) or the Z. mobilis ZM4 strain ( $g l f)$. The primers used to amplify the transporter genes were as follows:

5'-ACTCGAATTCATGAATACCCAGTATAATTC-3'

(forward primer) and 5'-ACTCCTGCAGTTACAGCGTAGCA G-3' (reverse primer) for $x y l E ; 5^{\prime}$-ACTCGAATTCATGCCTGAC GCTAA-3' (forward primer) and 5'-ACTCCTGCAGTTAATCG TGAGCG-3' (reverse primer) for galP; and 5'-ACTCGAATT CATGAGTTCTGAAAGTAGT-3' (forward primer) and $5^{\prime}$-AC TCCTGCAGCTACTTCTGGGAG-3' (reverse primer) for $g l f$.

The amplicons were inserted between the EcoRI-PstI sites of the plasmid to generate three individual plasmids.

To construct the plasmid designed to insert xylose catabolic genes, the spectinomycin resistance cassette was spliced from

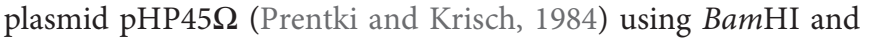
inserted into the pBluescript II SK+ plasmid at the BamHI site. The neutral site sequence (slr0168; hereafter called neutral site 2) (Kunert et al., 2000) was amplified from Synechocystis genomic DNA as upstream and downstream regions using the following primers:

5'-ACTCGGTACCATGACTATTCAATACACCC-3' (forward primer) and 5'-ACTCGTCGACCACCTGCACCAGACCA-3 ${ }^{\prime}$ (reverse primer) for the upstream region; and $5^{\prime}$-ACTCACTA GTTTGGGGCTGGCGGATT-3' (forward primer) and 5'-ACT 
CCCGCGGCTAAGTCAGCGTAAATCTG-3' (reverse primer) for the downstream region. The upstream and downstream fragments were inserted between the KpnI-SalI sites and SpeISacII sites of the plasmid, respectively. The $p s b A 2$ promoter and 5ST1T2 double terminator were amplified and cloned into the plasmid as described above. In the last step, the xylose catabolic genes $x y l A B$ were amplified from genomic DNA isolated from the $E$. coli $\mathrm{K}-12$ strain using the following primers:

\section{5'-ACTCGAATTCATGCAAGCCTATTTTGACCA-3'} (forward primer) and $5^{\prime}$-ACTCCCTGCAGGTTACGCCATTA ATGG-3' (reverse primer). The $x y l A B$ amplicon was inserted between the EcoRI-PstI sites of the plasmid.

Note that, in the case of $x y l A B$, only the region from the start codon of $x y l A$ to the end codon of $x y l B$ was amplified from the source organism; no other regulatory elements from the $x y l A B$ operon were included.

\section{Synechocystis Culture Conditions, Transformation, and Segregation}

Synechocystis strains were grown on solid or in liquid BG-11 medium at $30^{\circ} \mathrm{C}$ under $50 \mu \mathrm{E} \mathrm{m} \mathrm{m}^{-2} \mathrm{~s}^{-1}$ light intensity with shaking $(200 \mathrm{rpm})$. When $\mathrm{OD}_{730}$ reached $\sim 0.8$, transformations were carried out as described (Xue et al., 2014a). Once the presence of the heterologous insert was confirmed by PCR analysis, cells were streaked on BG-11 plates containing successively higher antibiotic concentrations followed by PCR tests to ensure complete segregation of the transformants.

\section{Reverse Transcription PCR}

Total RNA was isolated from 80-ml cultures of Synechocystis strains possessing the $x y l A B$ genes at $\mathrm{OD}_{730} \sim 0.7$, as previously described (Mohamed and Jansson, 1989). A Turbo DNA-Free Kit (Thermo Fisher Scientific) was used to remove contaminating genomic DNA. The reverse transcription reactions were carried out using Superscript III enzyme (Thermo Fisher Scientific) and random primers (New England BioLabs). The cDNA molecules thus synthesized were then used as templates for PCR, employing the same set of primers used to amplify the heterologous transporter-catabolic genes. The same primer sets were employed to check the negative controls, in which DNase-treated RNA molecules were used as templates. petA (sll1317), which was used as a positive control, was amplified using the following primers:

5'-ACTCGAATTCATGAGAAACCCTGATACTTTGGGGCT GTGGACGAAAAC-3' (forward primer) and 5' -ACTCCTGCAG CTAGAAATTAAGTTCGGCAGCTTGAACTTTTTCAATCTG$3^{\prime}$ (reverse primer). For a longer template, i.e., the $x y l A B$ genes, the SuperScript One-Step RT-PCR system for long templates (Thermo Fisher Scientific) was used as per manufacturer's instructions. PCR products were analyzed on a $0.8 \%$ agarose gel.

\section{Cell Extract Preparation, SDS-PAGE, and Immunoblot Analysis}

Synechocystis strains (wild-type and strains possessing the $x y l A B$ genes) were grown under the conditions described above, until $\mathrm{OD}_{730}$ reached $0.6-0.8$. Whole cell extracts were obtained and $20 \mu \mathrm{g}$ protein samples were electrophoresed as described (Xue et al., 2014a). After electrophoresis, gels were blotted onto nitrocellulose membranes using the Trans-Blot System (BioRad). Membranes were probed with XylA- and XylB-specific primary antibodies of rabbit origin (raised by Dr. Qiang Wang) and goat anti-rabbit alkaline phosphatase-conjugated secondary antibodies (Sigma-Aldrich). Antigen-antibody interactions were visualized using the BCIP/NBT Kit (Thermo Fisher Scientific).

\section{Demonstration of ${ }^{14} \mathrm{C}$-Labelled D-Xylose Uptake}

Synechocystis strains (wild-type and strains harboring the $x y l A B$ genes) were grown as described above, until the $\mathrm{OD}_{730}$ reached $\sim 0$. . Then, $10 \mathrm{ml}$ of the cells were washed thrice with BG11 medium and $\mathrm{OD}_{730}$ was adjusted to 0.6 . Next, $1 \mathrm{ml}$ of the cultures was grown in the presence of $400 \mathrm{nM}{ }^{14} \mathrm{C}$-labelled xylose [D- $\left.\left(1-{ }^{14} \mathrm{C}\right)\right]$ (American Radiolabeled Chemicals) in $10 \mathrm{ml}$ snapcapped glass tubes under similar growth conditions for $1 \mathrm{~h}$. Nine milliliters of BG-11 medium was added to the cultures and they were filtered through a $0.45 \mu \mathrm{m}$ pore-size nitrocellulose membrane (Bio-Rad). The membranes were washed thrice with $10 \mathrm{ml} \mathrm{BG}-11$ medium, air dried, and suspended in $10 \mathrm{ml}$ scintillation fluid (PerkinElmer) for $24 \mathrm{~h}$. Radioactivity was measured using an LS 6500 scintillation counter (Beckman).

\section{Biomass Measurement}

Synechocystis biomass was measured in terms of DW as previously described (Davies et al., 2014). Cultures of Synechocystis strains were initiated in $100 \mathrm{ml}$ BG-11 liquid medium at $30^{\circ} \mathrm{C}$ with shaking $(200 \mathrm{rpm})$ and an initial $\mathrm{OD}_{730}$ of 0.05 . The cultures were provided with: for autotrophic growth, $50 \mu \mathrm{E} \mathrm{m}^{-2} \mathrm{~s}^{-1}$ light; for mixotrophic growth, $5 \mathrm{mM}(750 \mathrm{mg} / \mathrm{L})$ xylose and/or $5 \mathrm{mM}$ glucose $(900.8 \mathrm{mg} / \mathrm{L})$ along with $50 \mu \mathrm{E} \mathrm{m}^{-2}$ $\mathrm{s}^{-1}$ light; for light-activated heterotrophic growth (hereafter LAHG) conditions (Anderson and McIntosh, 1991), $5 \mathrm{mM}$ xylose $(750 \mathrm{mg} / \mathrm{L})$ and/or $5 \mathrm{mM}$ glucose $(900.8 \mathrm{mg} / \mathrm{L})$ along with $50 \mu \mathrm{E} \mathrm{m} \mathrm{m}^{-2} \mathrm{~s}^{-1}$ light for $10 \mathrm{~min}$ per day; and for dark growth, neither sugar nor light. For the dark and LAHG cultures, biomass measurements were made every $24 \mathrm{~h}$ for 7 days, while for autotrophic and mixotrophic cultures, biomass values were estimated every $6 \mathrm{~h}$ for 3 days.

\section{Enzymatic Assays for Measurement of Sugar Uptake}

Enzymatic uptake assays were performed for cultures grown in the presence of $5 \mathrm{mM}$ xylose and $5 \mathrm{mM}$ each of xylose and glucose. One milliliter of culture, collected at the time points specified for biomass measurements, was immediately filtered using $0.45 \mu \mathrm{m}$ pore-size nylon membrane syringe filters (Fisher Scientific) to obtain cell-free media.

The amount of xylose present in the filtered medium fractions was measured using a D-Xylose Assay Kit (Megazyme) as per manufacturer's instructions. The sequential action of xylose mutarotase and $\beta$-xylose dehydrogenase generates NADH molecules. The amount of $\mathrm{NADH}$ is stoichiometric with that of $\mathrm{D}$-xylose and is calculated from the difference in $\mathrm{OD}_{340}$ values before and after $\beta$-xylose dehydrogenase action. 
The amount of glucose present in the filtered medium fractions was measured using the D-Glucose Assay KitGOPOD Format (Megazyme) as per manufacturer's instructions. Sequential action of glucose oxidase and peroxidase generates quinoneimine. The amount of dye formed is stoichiometric with that of $\mathrm{D}$-glucose and was calculated from $\mathrm{OD}_{510}$ values obtained for the samples relative to the $\mathrm{OD}_{510}$ value obtained for a standard.

Data obtained from the biomass measurements and the enzymatic assays were used to calculate the sugar uptake rates by the Synechocystis strains during each time interval, using a previously described mathematical formula (Munyon and Merchant, 1959).

\section{RESULTS}

\section{Construction of Synechocystis Strains Possessing Heterologous Xylose-Specific Genes}

Synechocystis strains possessing xylose transporter and catabolic genes were developed from a Synechocystis sp. PCC 6803 wildtype strain (hereafter WT). The construction process involved two rounds of transformation. In the first round, one of the three xylose transporter genes, $x y l E$ or galP from E. coli K-12 or glf from Z. mobilis ZM4, was introduced into neutral site 1 (Xue et al., 2014b) in WT Synechocystis via homologous recombination to generate three individual strains, $\mathrm{X}-\mathrm{Tr} 1, \mathrm{X}-\mathrm{Tr} 2$, and $\mathrm{X}-\mathrm{Tr}$, respectively (Table $\mathbf{1}$ ). The plasmid constructs designed for integration of the transporter genes included the $p s b A 2$ promoter of Synechocystis origin, 5ST1T2 double terminator of E. coli origin, kanamycin resistance cassette, neutral site 1 divided into $\sim 600$ bp upstream and $\sim 600$ bp downstream regions, and one of the three aforementioned transporter genes (Figure 2A).

In the second round of transformation, the $x y l A B$ genes, which are responsible for funneling xylose into the PPP, were introduced into neutral site 2 (Kunert et al., 2000) in the three Synechocystis strains generated in the first round of transformation as well as in the WT strain via homologous recombination to obtain four

TABLE 1 | Synechocystis strains used in this study.

\begin{tabular}{|c|c|c|}
\hline Strain & Genotype & Description \\
\hline WT & $\begin{array}{l}\text { Wild-type } \\
\text { Synechocystis sp. } \\
6803\end{array}$ & Wild-type genomic sequence \\
\hline$X-\operatorname{Tr} 1$ & $x y I E-\Delta$ Neu 1 & xylE inserted at neutral site 1 (near slr1285) \\
\hline $\mathrm{X}-\mathrm{Tr} 2$ & galP- $\Delta$ Neu 1 & galP inserted at neutral site 1 (near slr1285) \\
\hline $\mathrm{X}-\operatorname{Tr} 3$ & glf- $\Delta$ Neu 1 & glf inserted at neutral site 1 (near s/r1285) \\
\hline $\mathrm{X}-U \mathrm{t} 1$ & $\begin{array}{l}x y I E-\Delta \text { Neu } \\
1:: x y \mid A B-\Delta \text { Neu } 2\end{array}$ & $\begin{array}{l}\text { xylE inserted at neutral site } 1 \text { (near s/r1285), } \\
x y I A B \text { genes inserted at neutral site } 2 \text { (s/r0168) }\end{array}$ \\
\hline $\mathrm{X}-U \mathrm{t} 2$ & $\begin{array}{l}\text { galP- } \Delta \text { Neu } \\
1:: x y \mid A B-\Delta \text { Neu } 2\end{array}$ & $\begin{array}{l}\text { galP inserted at neutral site } 1 \text { (near s/r1285), } \\
\text { xyIAB genes inserted at neutral site } 2 \text { (s/r0168) }\end{array}$ \\
\hline$X-U t 3$ & $\begin{array}{l}\text { glf- } \Delta \text { Neu } \\
1:: x y \mid A B-\Delta \text { Neu } 2\end{array}$ & $\begin{array}{l}\text { glf inserted at neutral site } 1 \text { (near s/r1285), } \\
\text { xylAB genes inserted at neutral site } 2 \text { (s/r0168) }\end{array}$ \\
\hline $\mathrm{X}-\mathrm{Ut} 4$ & $x y \mid A B-\Delta$ Neu 2 & $x y I A B$ genes inserted at neutral site 2 (s/r0168) \\
\hline
\end{tabular}

resultant strains, X-Ut1, X-Ut2, X-Ut3, and X-Ut4 (Table 1). The plasmid construct designed to integrate the xylose catabolic genes included the same promoter and transcriptional terminator as used in the transporter gene-specific plasmid constructs, the spectinomycin resistance cassette, neutral site 2 divided into $\sim 970$ bp upstream and $\sim 970$ bp downstream regions, and $x y l A B$ genes (Figure 2B). The $x y l A B$ genes consist of two individual genes, $x y l A$ (encoding $\mathrm{D}$-xylose isomerase) and $x y l B$ (encoding $\mathrm{D}$-xylulokinase), along with the ribosomal binding site (hereafter RBS) present between them.

We used the native $p s b A 2$ promoter to drive expression of both the transporter genes and the catabolic genes. psbA2 is a strong, light-sensitive promoter that enhances gene expression under high light conditions (Mohamed and Jansson, 1989) and regulates the expression of heterologous genes in response to variations in light intensity (Lindberg et al., 2010). This promoter has been used to express a number of heterologous genes (Zhou et al., 2014).

\section{Insertion of Heterologous Genes and Segregation of the Transformant Strains}

The transporter as well as xylose utilization-specific heterologous genes were introduced into the neutral sites of the Synechocystis genome by homologous recombination. After each round of transformation, putative transformants were checked for the presence of heterologous gene inserts. Cells from one of the transformant colonies were cultivated successively under increasing antibiotic pressure to achieve complete segregation, in which selection of only those cells that had acquired all the genome copies carrying the insert was ensured. Only after confirmation of segregation, were strains used for the next round of transformation and further work.

For the PCR analyses represented in Figures 3A,B, the three strains generated after the first round of transformation, i.e., $\mathrm{X}-\operatorname{Tr} 1, \mathrm{X}-\mathrm{Tr} 2$, and $\mathrm{X}-\mathrm{Tr} 3$, were used. To verify the presence of transporter-specific heterologous genes, the same sets of primers used to amplify the respective genes from genomic DNA of source organisms were employed (A1/A2 for $x y l E$, B1/B2 for galP, and C1/C2 for glf, Figure 2A), which generated products of approximately $1.48,1.40$, and $1.42 \mathrm{~kb}$ in length, respectively (Figure $\mathbf{3 A}$ ). To verify segregation, the forward primer used to amplify the upstream region of neutral site 1 and the reverse primer used to amplify the downstream region of neutral site 1 were employed (D1/D2, Figure 2A), and extension times in the PCR cycles were set specifically to amplify the wild-type (uninterrupted) neutral site 1 . PCR amplifications yielded a $\sim 1.20-\mathrm{kb}$ band representing neutral site 1 in the WT strain, but failed to generate any product for the transformants, indicating the absence of uninterrupted neutral site 1 and hence complete segregation of the strains (Figure 3B).

To test for the presence of the catabolic genes $x y l A B$ in the strains obtained after the second round of transformation, i.e., X-Ut1, X-Ut2, X-Ut3, and X-Ut4, the same set of primers used to amplify the genes from genomic DNA of the source organism was employed (E1/E2, Figure 2B), which generated 
A

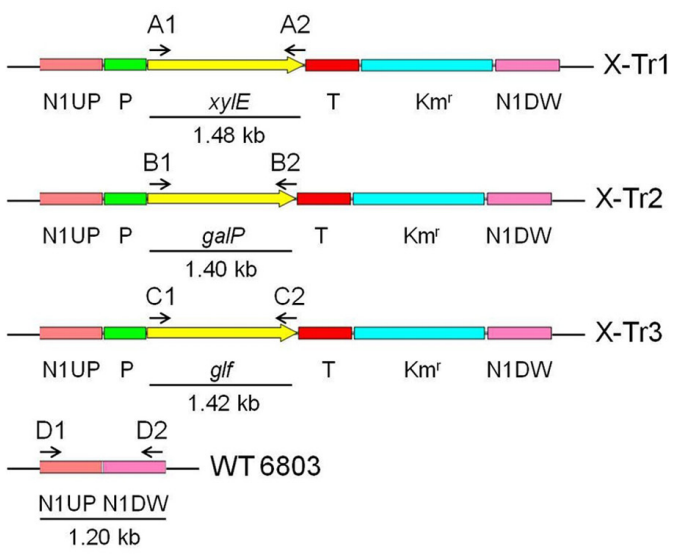

B

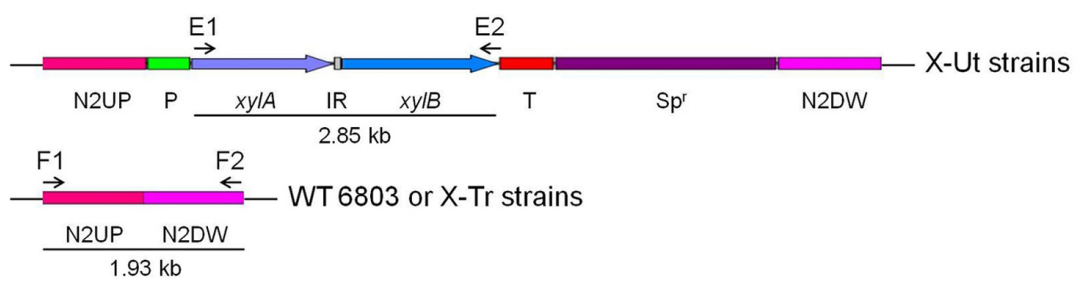

FIGURE 2 | Transformation of Synechocystis strains. All transgenes used in the study were expressed under the control of the psbA2 promoter (Prm) and 5ST1T2 terminator (Trm). Intergenic region (IR), if present between individual genes, is represented as a gray box. Numbered letters and arrows represent the primer sets used to insert genes and evaluate segregation, and the direction of the amplifications, respectively. (A) Genes encoding the xylose transporters were inserted into neutral site 1 in the wild-type Synechocystis genome using upstream (N1UP) and downstream (N1DW) regions for homologous recombination. The kanamycin resistance cassette $\left(\mathrm{Km}^{r}\right)$ was used for selection and segregation of the transformants. (B) The xylAB genes, encoding enzymes that funnel xylose into the pentose phosphate pathway, were inserted into neutral site 2 in the genomes of Synechocystis strains carrying one of the three xylose transporter genes and the wild-type strain using upstream (N2UP) and downstream (N2DW) regions for homologous recombination. The spectinomycin resistance cassette (Spr) was used for selection and segregation of the transformants.

products of approximately $2.85 \mathrm{~kb}$ in length (Figure 3C). To verify the segregation with respect to neutral site 2, the forward primer used for amplification of the upstream region of neutral site 2 and the reverse primer used for amplification of the downstream region of neutral site 2 were employed (F1/F2, Figure 2B), and extension times in the PCR were set specifically to amplify wild-type neutral site 2. PCR amplifications yielded a $\sim 1.93-\mathrm{kb}$ band representing neutral site 2 in the WT strain, but failed to generate any product for the transformants, indicating the absence of uninterrupted neutral site 2 and hence complete segregation of the strains (Figure 3D).

\section{Expression of Heterologous Genes at the Transcriptional Level}

Once the segregation of the strains obtained after the second round of transformation was confirmed, transcription of the heterologous genes for the transporters and the catabolic genes in the X-Ut1, X-Ut2, X-Ut3, and X-Ut4 strains was examined by RT-PCR. For the expression studies, both a positive and negative control were included. For the positive control, expression of petA (sll1317), which encodes apocytochrome $f$, a core subunit of the cytochrome $b_{6} f$ complex, was tested. As a negative control for each strain, we examined whether the corresponding heterologous genes could be amplified from DNase-treated RNA samples obtained from each strain by PCR, to confirm the absence of any leftover DNA in the RNA samples.

When cDNA samples from the aforementioned strains were subjected to PCR using the same primer sets used to confirm gene insertion, products of the expected size were amplified. A $\sim 0.98$ $\mathrm{kb}$ band was present for all positive controls and heterologous gene-specific bands were absent in the negative controls for all strains (Figures 4A,B). These results indicate the successful transcription of all the heterologous genes and corroborate the quality of the RNA samples.

\section{Expression of the Catabolic Genes at the Translational Level}

To study the expression of the xylose catabolic genes, $x y l A$ and $x y l B$, at the protein level, specific polyclonal antibodies were raised by Dr. Qiang Wang (Institute of Hydrobiology, Wuhan, China) against XylA and XylB proteins overexpressed in E. coli. The antibodies were used to detect the presence of the proteins in the total cell extracts obtained from the X-Ut1, X-Ut2, X-Ut3, and 


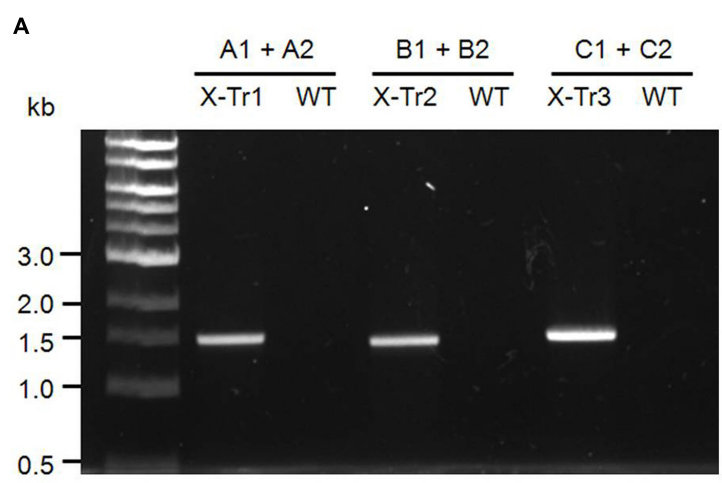

C



B

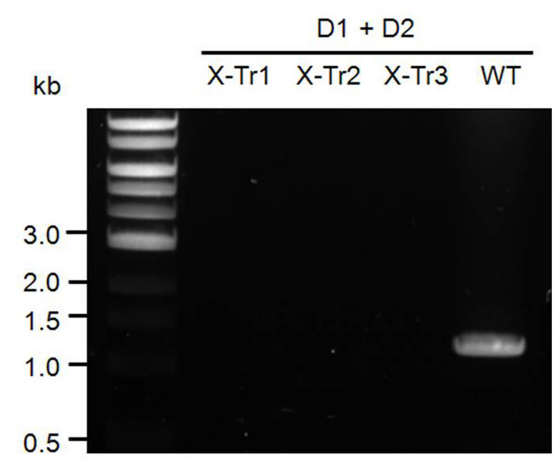

D

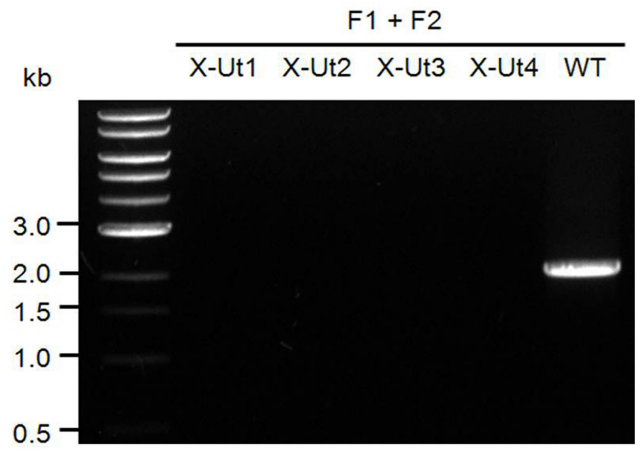

FIGURE 3 | Test of insertion of heterologous genes and chromosomal segregation for Synechocystis strains. (A) Primers upstream and downstream of the xylose transporter genes xylE (A1-A2), galP (B1-B2), and glf (C1-C2) were used to confirm the presence of the inserts in the respective transformants (Figure 2A) and also in the WT strain as the negative control. In the presence of the templates, primers A1-A2, B1-B2, and C1-C2 produced fragments of 1.48, $\sim 1.40$, and $\sim 1.42 \mathrm{~kb}$, respectively. (B) Primers upstream and downstream of intact neutral site 1 (D1-D2) were used to examine the chromosomal segregation for respective transformants (Figure 2A) along with the WT strain as a positive control. In the absence of uninterrupted neutral site 1, primers D1-D2 failed to produce PCR products in the transformants, whereas the WT strain yielded a $\sim 1.20-\mathrm{kb}$ product. (C) Primers upstream and downstream of the xylose catabolic genes $x y / A B$ (E1-E2) were used to examine the insert in respective transformants (Figure 2B) and also in the WT strain as the negative control. In the presence of the template, primers E1-E2 produced a product of $\sim 2.85 \mathrm{~kb}$. (D) Primers upstream and downstream of intact neutral site 2 (F1-F2) were used to check the chromosomal segregation for respective transformants (Figure 2B) along with the WT strain as the positive control. In the absence of uninterrupted neutral site 2, primers F1-F2 failed to produce PCR products in the transformants, whereas the WT strain yielded a $\sim 1.93$-kb product.

$\mathrm{X}$-Ut4 strains, and the WT strain was used as the negative control. XylA protein, with a molecular weight of $\sim 44 \mathrm{kD}$ (Schellenberg et al., 1984), was present in the total cell extracts obtained from the transformants. Similarly, the presence of XylB protein, with an estimated molecular weight of $\sim 52 \mathrm{kD}$ (Lawlis et al., 1984), was detected in the cell extracts isolated from the transformant strains (Figure 5). Expression of $\mathrm{XylB}$ showed that the RBS present between $x y l A$ and $x y l B$ of $E$. coli origin functioned in Synechocystis. Antibodies probing both of these proteins showed no cross-reaction with proteins present in the WT cell extract.

\section{Uptake Assay of D- $\left[{ }^{14} \mathrm{C}\right]$ Xylose as a Demonstration of Transporter Activity}

To probe the activity of xylose transporter proteins in Synechocystis, we tested the ability of the X-Ut1, X-Ut2, X-Ut3, and X-Ut4 strain and also of the WT strain to take up D- $\left[{ }^{14} \mathrm{C}\right]$ xylose. At the end of a 1-h incubation period, the strains showed various degrees of radioactivity. The levels of radioactivity in
$\mathrm{X}$-Ut1, X-Ut2, X-Ut3, and X-Ut4 were $\sim 653 \%, \sim 136 \%$, $77 \%$, and $\sim 100 \%$ greater than those observed in the WT strain (Figure 6). Thus, the transformants were better able to take up and use xylose than was the WT.

\section{Study of Biomass Accumulation Under Various Conditions}

To study and compare the growth patterns exhibited by the strains generated after the first and second transformation events and the WT strain, we cultured the strains under different conditions (described in Materials and Methods). Biomass, i.e., DW, measurements were taken at 24-h intervals for 7 days in the case of dark and light-activated heterotrophic growth (LAHG) conditions and at 6-h intervals for 3 days for autotrophy and mixotrophy. In the absence of xylose, biomass yields were similar for all the strains. None of the strains were able to grow in darkness (data not shown). Under LAHG conditions in the presence of $5 \mathrm{mM}$ glucose (hereafter LAHG-glucose conditions), 
A

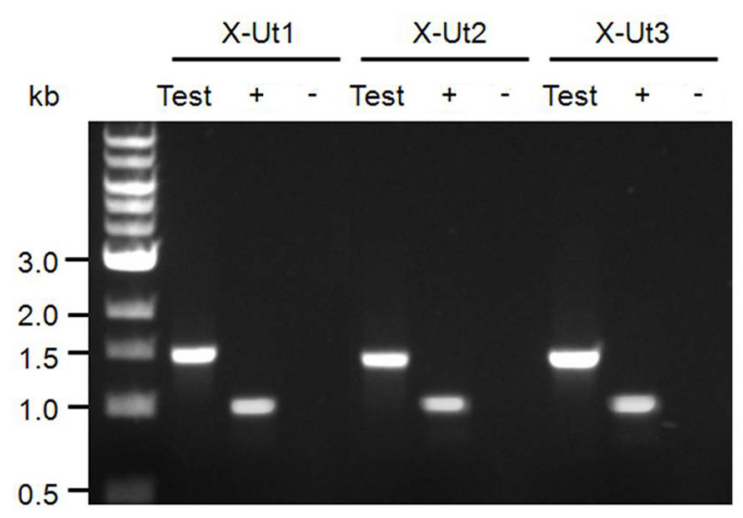

B

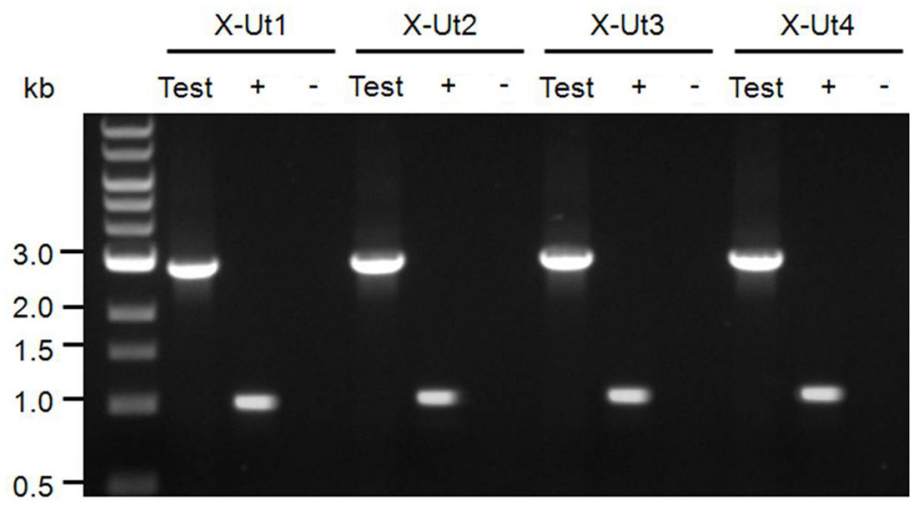

FIGURE 4 | Transcription evaluation of xylose-specific genes. (A) Primers upstream and downstream of the xylose transporter genes xylE (A1-A2), galP (B1-B2), and glf (C1-C2) were used (Figure 2A) to examine whether these genes were transcribed in the corresponding strains represented as 'Test.' In the presence of the templates, primers A1-A2, B1-B2, and C1-C2 produced products of $\sim 1.48, \sim 1.40$, and $\sim 1.42$ kb in length, respectively. (B) Primers upstream and downstream of the xylose catabolic genes xylAB (E1-E2) were used (Figure 2B) to evaluate the transcription of the genes in the corresponding strains represented as 'Test.' In the presence of the templates, primers E1-E2 produced products of $\sim 2.85 \mathrm{~kb}$. For the positive control (+), transcription of petA was examined using a gene-specific primer pair. The primer set produced a $\sim 0.99-\mathrm{kb}$ product from cDNA templates of the transformants. For the negative control (-), amplification of heterologous genes from the corresponding RNA samples was evaluated using the gene-specific primer pairs. The primer pairs failed to generate any PCR product, indicating the absence of DNA contamination in the RNA samples.

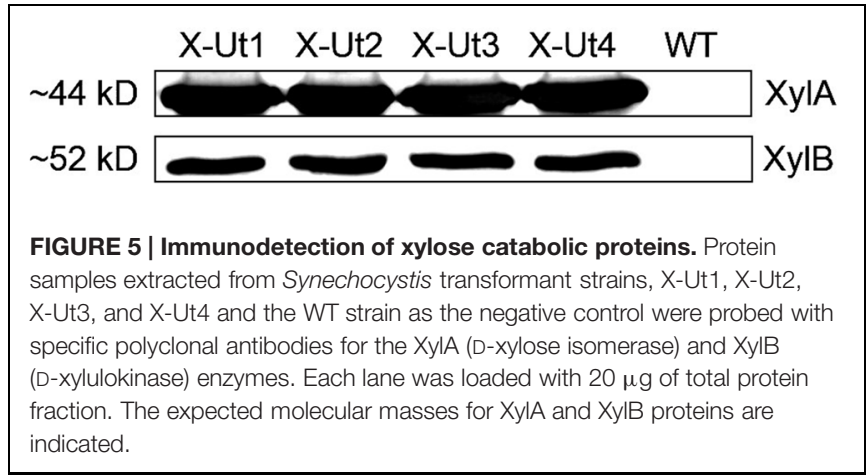

at the end of the seventh day, the strains showed biomass yields of $0.329 \pm 0.010 \mathrm{~g} / \mathrm{L}$. Under autotrophy and mixotrophy in the presence of $5 \mathrm{mM}$ glucose (hereafter mixotrophy-glucose conditions), at the end of third day, the biomass yields obtained for all strains were $0.244 \pm 0.015 \mathrm{~g} / \mathrm{L}$ and $0.993 \pm 0.013 \mathrm{~g} / \mathrm{L}$, respectively.

Under LAHG conditions in the presence of $5 \mathrm{mM}$ xylose (hereafter LAHG-xylose conditions), only X-Ut1, X-Ut2, X-Ut3, and X-Ut4 strains exhibited growth (data not shown for WT, $\mathrm{X}-\operatorname{Tr} 1, \mathrm{X}-\mathrm{Tr} 2$, and $\mathrm{X}-\operatorname{Tr} 3$; Figure 7A). Under mixotrophy conditions in the presence of $5 \mathrm{mM}$ xylose (hereafter mixotrophyxylose conditions), the WT, X-Tr1, X-Tr2, and X-Tr3 strains showed biomass yields of $0.331 \pm 0.014 \mathrm{~g} / \mathrm{L}$, which were similar to those obtained when grown under autotrophy, indicating the inability of the strains to utilize xylose. However, the X-Ut1, $\mathrm{X}-\mathrm{Ut} 2, \mathrm{X}-\mathrm{Ut} 3$, and X-Ut4 strains showed greater biomass yields under mixotrophy-xylose conditions than under autotrophy (Figures 8A,B). Biomass accumulation results demonstrate that all four of the transformants carrying the catabolic genes,

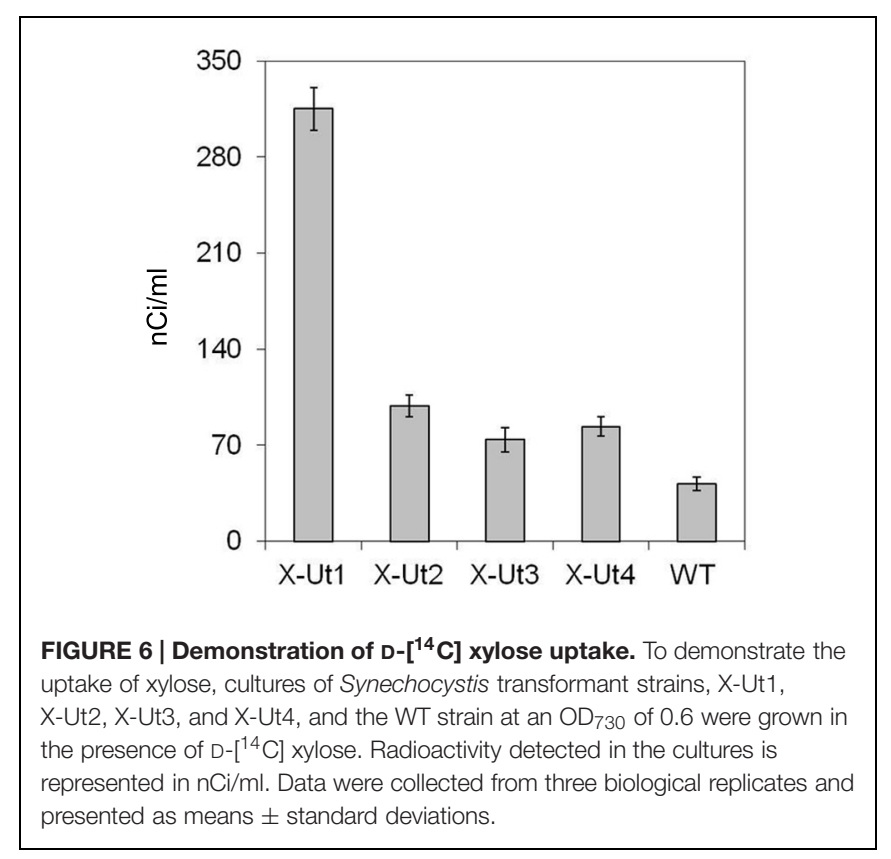

namely X-Ut1, X-Ut2, X-Ut3, and X-Ut4, utilize xylose. After 7 days of culture under LAHG-xylose conditions, the X-Ut1, $\mathrm{X}$-Ut2, and X-Ut3 strains showed $\sim 62,28$, and $\sim 60 \%$ greater biomass yields than did X-Ut4, respectively (Figure 7A). Under mixotrophy-xylose conditions, the strains carrying heterologous transporters showed higher biomass values at each time point. Notably, at the end of the second day of culture, X-Ut1, $\mathrm{X}$-Ut2, and X-Ut3 strains showed $\sim 92, \sim 34$, and $\sim 94 \%$ greater biomass values than did the X-Ut4 strain (Figure 8B). For both LAHG-xylose and mixotrophy-xylose conditions, biomass 
A

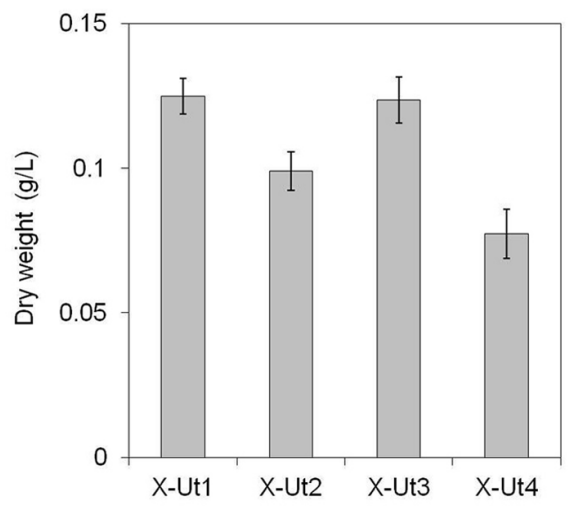

B

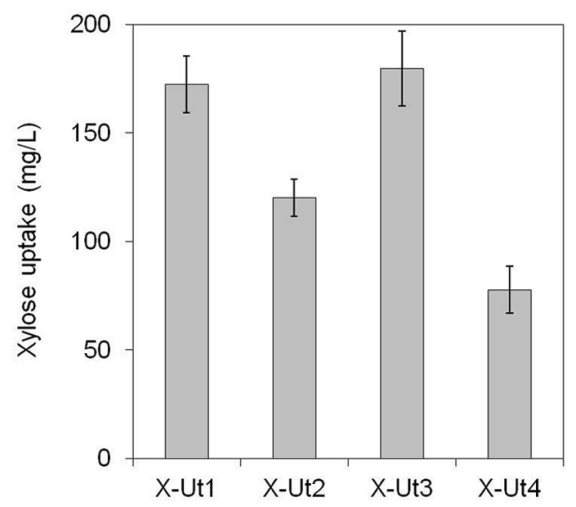

FIGURE 7 | Growth and xylose consumption under LAHG conditions in the presence of $\mathbf{5}$ mM xylose. Synechocystis strains X-Ut1, X-Ut2, X-Ut3, and X-Ut4 were grown in the presence of $5 \mathrm{mM}(750 \mathrm{mg} / \mathrm{L})$ xylose. (A) Dry biomass values estimated at the end of the seventh day. (B) Xylose consumption at the end of the seventh day exhibited by the transformant strains, determined from the measurement of residual xylose in the cell-free medium. Data were collected from three biological replicates and are presented as means \pm standard deviations.

measurement data for X-Ut1, X-Ut2, X-Ut3, and X-Ut4 strains at each time point are presented in Supplementary Figures S1A and S2A.

To examine the ability of the xylose consuming strains to grow in the presence of xylose and glucose, we cultured the strains under LAHG and mixotrophic conditions in medium supplemented with $5 \mathrm{mM}$ each of xylose and glucose (hereafter LAHG-mixed sugar and mixotrophy-mixed sugar conditions). The xylose consuming strains showed similar biomass yields under both conditions, in contrast to the variable yields exhibited in the presence of xylose alone (Figures 7A, 8A,B and 9A). The absence of two distinct growth phases and the simultaneous uptake of both the sugars did not indicate diauxie in these strains (data not shown).

\section{Sugar Uptake Assays}

To measure xylose uptake by the strains generated after each transformation event and by the WT strain, we first cultured the strains under LAHG-xylose and mixotrophy-xylose conditions. The WT, X-Tr1, X-Tr2, and X-Tr3 strains that lacked the catabolic genes $x y l A B$ showed no change in the amount of residual xylose in the medium at the tested time points, indicating their inability to utilize xylose (data not shown). On the other hand, the X-Ut1, X-Ut2, X-Ut3, and $\mathrm{X}$-Ut4 strains that possessed the $x y l A B$ genes showed varying degrees of xylose consumption under both growth conditions (Figures 7B and 8C). After 7 days of culture under LAHGxylose conditions, xylose consumption was $\sim 122,55$, and $\sim 131 \%$ greater in the $\mathrm{X}-\mathrm{Ut} 1, \mathrm{X}-\mathrm{Ut} 2$, and $\mathrm{X}-\mathrm{Ut} 3$ strains, respectively, than in X-Ut4 (Figure 7B). Under the same conditions, the maximum xylose uptake rates exhibited by the X-Ut1, X-Ut2, and X-Ut3 strains were $\sim 78, \sim 45$, and $\sim 80 \%$ higher than that exhibited by X-Ut4 (Figure 10A). Under mixotrophyxylose conditions, the strains carrying heterologous transporters showed higher xylose uptake than did the strain relying only on endogenous transporter/s at each time point. Notably, at the end of the second day of culture, the X-Ut1, X-Ut2, and X-Ut3 strains showed $\sim 205, \sim 80$, and $\sim 209 \%$ higher levels of xylose uptake than did X-Ut4 (Figure 8C). Under the same conditions, the maximum xylose uptake rates exhibited by the X-Ut1, X-Ut2, and X-Ut3 strains were $\sim 64, \sim 26$, and $\sim 65 \%$ higher than that exhibited by X-Ut4 (Figure 10B). For both LAHG-xylose and mixotrophy-xylose conditions, the sugar uptake data at each time point are presented in Supplementary Figures S1B and S2B.

When grown under LAHG and mixotrophy-mixed sugar conditions, the xylose consuming strains, X-Ut1, X-Ut2, X-Ut3, and $\mathrm{X}-\mathrm{Ut4}$, consumed similar amounts of xylose (Figure 9B), in accordance with the biomass accumulation data. Under LAHGmixed sugar conditions, all of the glucose was consumed by the end of the sixth day, while under mixotrophy-mixed sugar conditions, all of the glucose was consumed by the end of $48 \mathrm{~h}$ (data not shown). In the presence of mixed sugars, the maximum sugar uptake rates exhibited by the xylose consuming strains were very similar, in contrast to the results obtained when xylose was the only organic carbon source. Also, a sharp reduction in the maximum xylose uptake rates was observed when glucose was present along with xylose compared to when xylose was the sole sugar, with the exception of the X-Ut4 strain, which exhibited similar maximum xylose uptake rates under LAHG-xylose and LAHG-mixed sugar conditions (Figures 10A,B; Supplementary Table S1).

When xylose was the sole organic carbon source, the X-Ut1 and X-Ut3 strains were the most efficient in terms of biomass accumulation and xylose uptake, X-Ut2 was intermediately efficient, and X-Ut4 was the least efficient. When glucose was used in addition to xylose, no significant difference was observed in the growth and xylose consumption patterns among the xylose consuming strains, in the defined period of study. These results demonstrate that heterologous expression of 


\section{A}

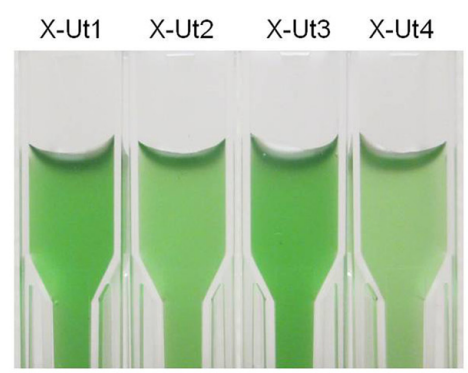

B

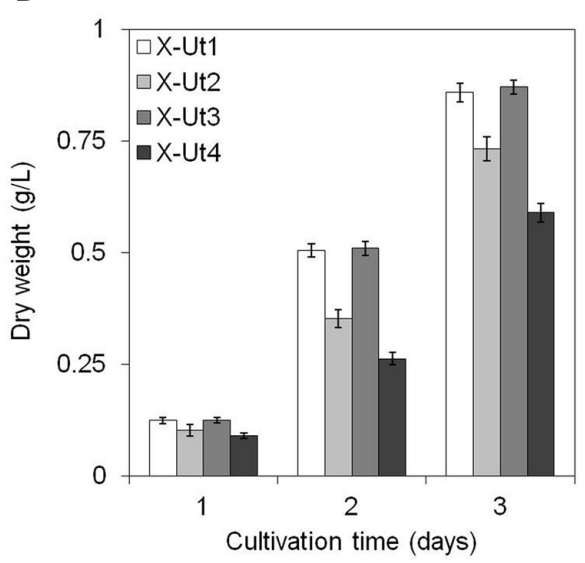

C

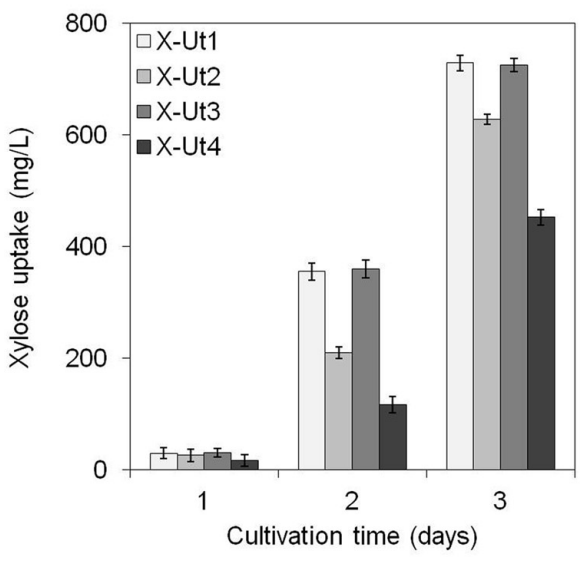

FIGURE 8 | Growth and xylose consumption under mixotrophy in the presence of $5 \mathrm{mM}$ xylose. Synechocystis strains X-Ut1, X-Ut2, X-Ut3, and X-Ut4 were grown in the presence of $5 \mathrm{mM}(750 \mathrm{mg} / \mathrm{L})$ xylose. (A)

Photograph depicting differential growth shown by the transformant strains at the end of second day of culture. (B) Dry biomass values estimated at the end of first, second, and third days. (C) Xylose consumption at the end of the first, second, and third day exhibited by the transformant strains, determined from the measurement of residual xylose in filtered cell-free medium. Data represented in graphs were collected from three biological replicates and presented as means \pm standard deviations.

XylE, GalP, and Glf enhances xylose transport in Synechocystis, which results in more organic carbon being available for growth and metabolism via the engineered isomerase catabolic pathway.

\section{DISCUSSION}

In this study, we sought to construct and compare Synechocystis strains that were able to utilize xylose by the heterologous expression of genes native to E. coli and Z. mobilis. Since Synechocystis is a mesophilic Gram negative cyanobacterium, heterologous genes derived from other Gram-negative mesophiles, especially the ones encoding the transporters, were expected to function in the host strain. E. coli is naturally capable of utilization of xylose and its genes involved in the xylose metabolism have been used to engineer other bacteria and yeasts (Zhang et al., 1995; Kawaguchi et al., 2006; Meijnen et al., 2008; Young et al., 2010; Xiong et al., 2012; McEwen et al., 2013; Lee et al., 2015). Although Z. mobilis is not a natural xylose utilizer, its glucose transporter, Glf is able to take up xylose very efficiently and has been functionally expressed in E. coli in either modified or unmodified form (Weisser et al., 1995; Chen et al., 2009; Ren et al., 2009). Hence, E. coli and Z. mobilis were chosen as the source organisms for xylose specific genes in the study. Although Synechocystis was considered to lack xylose transporters, we independently, alongside another recent study (Lee et al., 2015), found that expression of the $x y l A B$ genes alone was sufficient to generate lines that could utilize xylose (Figures $7 \mathbf{A}, \mathbf{B}$ and $\mathbf{8 A}-\mathbf{C}$ ), indicating the involvement of endogenous sugar transporter/s. This also indicates that the xylose uptake observed in strains possessing non-native transporters was due to activities of both endogenous and heterologous transporters. GlcP (sll0771) is the only known MFS-type glucose transporter identified in Synechocystis (Lee et al., 2015), and this transporter shows an affinity for fructose as well (Zhang et al., 1989). Two of the heterologous MFStype transporter proteins used in the study have also been shown to possess specificity for more than one substrate. The proton symporter GalP of E. coli origin, which is primarily a galactose transporter, is able to transport an array of other substrates, including xylose (Baldwin and Henderson, 1989). Similarly, the uniporter Glf of Z. mobilis origin, which is primarily a glucose transporter, is also able to transport fructose and xylose (Saier and Crasnier, 1996).

Our results either directly or indirectly show that we successfully expressed the xylose catabolic genes $x y l A B$ in Synechocystis (Figures 5, 6, 7A,B and $\mathbf{8 A - C}$ ), indicating that the E. coli RBS functions in Synechocystis. Heterologously expressed E. coli $x y l A B$ and $x y l F G H$ genes, which encode xylose catabolic enzymes and an ATP-binding cassette (ABC)type transporter and contain unmodified RBSs, were recently shown to be involved in xylose transport and catabolism in engineered Synechocystis (Lee et al., 2015). In this work, we have compared the performance of Synechocystis strains engineered to catabolize xylose, relying on the native, non-specific xylose transporter/s with or without one of the three heterologous MFS type transporter proteins. With this strategy, we attempted to compare the performance of heterologous transporter proteins when expressed individually in Synechocystis, under LAHG and mixotrophic conditions. Unlike some other cyanobacterial 
A

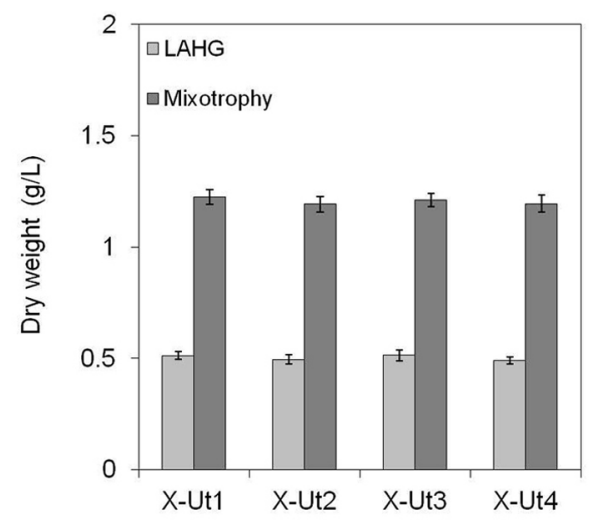

B

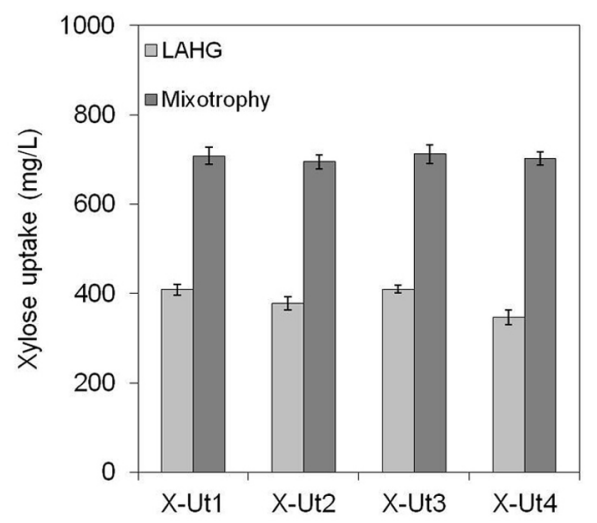

FIGURE 9 | Growth and xylose consumption in the presence of $\mathbf{5} \mathbf{~ m M}$ xylose and glucose. Synechocystis strains X-Ut1, X-Ut2, X-Ut3, and X-Ut4 were grown in the presence of $5 \mathrm{mM}(750 \mathrm{mg} / \mathrm{L})$ xylose and $5 \mathrm{mM}(900.8 \mathrm{mg} / \mathrm{L})$ glucose. (A) Dry biomass values estimated at the end of the seventh day for the LAHG condition and at the end of the third day for mixotrophy. (B) Xylose consumption at the end of the seventh day for the LAHG condition and at the end of the third day for mixotrophy, determined by the measurement of residual xylose in the cell-free medium. Data were collected from three biological replicates and presented as means \pm standard deviations.

A

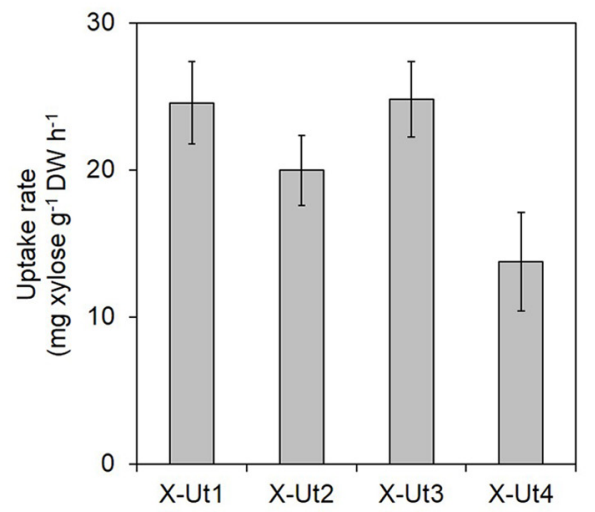

B

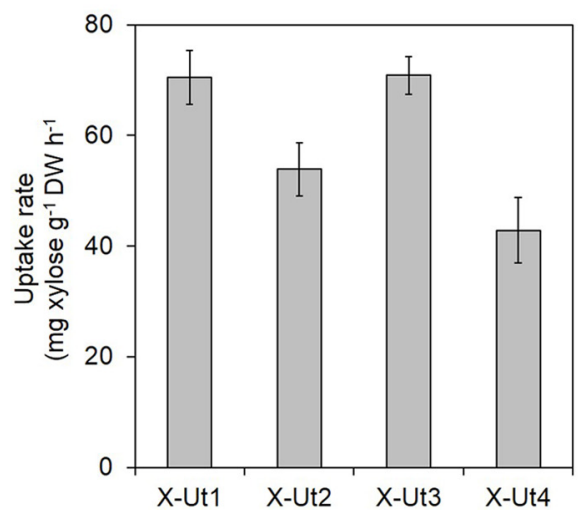

FIGURE 10 | Maximum xylose uptake rates in the presence of $\mathbf{5} \mathbf{~ m M}$ xylose. Synechocystis strains X-Ut1, X-Ut2, X-Ut3, and X-Ut4, were grown in the presence of $5 \mathrm{mM}(750 \mathrm{mg} / \mathrm{L})$ xylose. Maximum xylose uptake rates [mg xylose $\mathrm{g}^{-1}$ dry weight (DW) $\mathrm{h}^{-1}$ ] under (A) LAHG and (B) mixotrophy conditions were calculated using a previously described formula (Munyon and Merchant, 1959). For all the strains, maximum xylose uptake rates were observed between the sixth and seventh day under LAHG. Under mixotrophy, maximum xylose uptake rates were observed between the 42 and $48 \mathrm{~h}$ (for X-Ut1, X-Ut3, and X-Ut4) and the 48 and $54 \mathrm{~h}$ (for X-Ut2). Raw data were collected from three biological replicates. Uptake rates are presented as means \pm standard deviations.

species, Synechocystis is unable to grow heterotrophically under complete darkness, and requires brief exposure to light for growth. This type of growth has been termed as light activated heterotrophic growth, i.e., LAHG (Anderson and McIntosh, 1991). For LAHG conditions, we illuminated Synechocystis cultures daily with $50 \mu \mathrm{E} \mathrm{m} \mathrm{m}^{-2} \mathrm{~s}^{-1}$ light for $10 \mathrm{~min}$, which we consider just sufficient to support heterotrophic growth. Under LAHG-xylose conditions, Synechocystis strains lacking the xylose catabolic genes did not show any growth (data not shown). This indicates that, the growth exhibited by the strains expressing $x y l A B$ genes was the result of utilization of xylose and not due to photosynthetic electron transport. Lee et al. (2015) have compared the growth of a Synechocystis strain expressing $x y l A B$ genes with another strain expressing $x y l A B$ and transporter coding $x y l F G H$ genes in the presence of four different concentrations of xylose, under modified LAHG conditions wherein the cultures received daily illumination of $50 \mu \mathrm{E} \mathrm{m} \mathrm{m}^{-2} \mathrm{~s}^{-1}$ for $1 \mathrm{~h}$. At the end of ninth day under modified LAHG conditions, the latter strain reached higher optical density values only at xylose concentrations of 10 and $50 \mathrm{mM}$ (Lee et al., 2015). We sought to use xylose concentration as low as possible, to evaluate the xylose catabolizing strains on the basis of biomass accumulation and xylose consumption data collected 
at 6-h intervals for 3 days under mixotrophy and 24-h intervals for 7 days under LAHG conditions. In contrast to the results obtained for the Synechocystis strain carrying the XylFGH transporter (Lee et al., 2015), we found that expression of heterologous xylose transporters was able to boost the ability of transformants to utilize xylose, even at low xylose concentrations $(5 \mathrm{mM})$, when it was the sole source of organic carbon. X-Ut2, showed an intermediate ability to utilize xylose, and was more efficient than the $\mathrm{X}-\mathrm{Ut} 4$ strain. The performance of $\mathrm{X}-\mathrm{Ut} 1$ and $\mathrm{X}-\mathrm{Ut} 3$ was the most remarkable (Figures 7A,B, 8A-C and 10A,B). Thus, among the heterologous transporters studied, GalP was the least efficient. However, we were unable to determine which of the other two transporters, XylE and Glf, was more active, since a bottleneck may exist that influences the catabolic activities of XylAB or enzymes of the PPP of Synechocystis. We did not find any significant difference in the biomass yields of $\mathrm{X}-\mathrm{Ut} 1$ and $\mathrm{X}-\mathrm{Ut} 3$ strains grown in the presence of 10 and $20 \mathrm{mM}$ xylose under mixotrophic conditions at the end of third day (data not shown). During preliminary experiments performed in our laboratory, we observed that the WT, X-Tr1, X-Tr2, and X-Tr3 strains that lacked the $x y l A B$ genes and hence the ability to catabolize xylose showed no difference in growth under mixotrophyxylose (up to $20 \mathrm{mM}$ xylose) and autotrophy conditions (data not shown). These observations indicate the absence of osmotic stress and the presence of an efficient efflux system in Synechocystis.

Although X-Ut3 was one of the two most efficient strains in terms of dry biomass accumulation and xylose uptake (Figures 7A,B, 8A-C and 10A,B), it showed the lowest radioactivity among the xylose utilizing strains in the $D-\left[{ }^{14} \mathrm{C}\right]$ xylose uptake study (Figure 6). This can be explained by the bidirectional transport ability of Glf (Marger and Saier, 1993). When heterologously expressed in the cyanobacterium Synechococcus elongatus PCC 7942, Glf has been shown to export monomeric sugars (Niederholtmeyer et al., 2010). On the other hand, X-Ut1 showed significantly higher levels of radioactivity. These results are not reflected in the actual growth and xylose consumption data (Figures 6, 7A,B and 8A-C), indicating that a lag phase exists before xylose metabolism is fully established.

When glucose was included in the medium along with xylose, the maximum xylose uptake rates exhibited by the transformants were lower than those when xylose was the sole source of organic carbon (Figures 10A,B; Supplementary Table S1). This observation is in accordance with results obtained previously in which a Synechocystis strain carrying the $x y l A B$ genes showed a decrease in xylose consumption in the presence of glucose (Lee et al., 2015). Although glucose was consumed at a much faster rate than xylose (Supplementary Table S1), both sugars were utilized simultaneously with no signs of diauxy (data not shown). These results were expected, since $p s b A 2$ is a light-dependent promoter (Mohamed and Jansson, 1989; Lindberg et al., 2010). Absence of a regulatory region linked to the promoter which can be affected by presence of a sugar and continuous exposure to light caused constant induction of the $p s b A 2$ promoter, hence ensuring the expression of the xylose transporter and catabolic genes even in the presence of glucose. In the presence of $5 \mathrm{mM}$ each of xylose and glucose, the growth and sugar consumption patterns exhibited by the Synechocystis strains carrying the $x y l A B$ genes were found to be similar to each other, which may indicate that the Synechocystis strains had reached their maximum capacity to process organic carbon, at least via PPP in the presence of $5 \mathrm{mM}$ glucose. Although diauxy was not observed, the presence of glucose caused a decrease in the maximum xylose uptake rates, with the exception of the X-Ut4 strain under LAHG-mixed sugar conditions (Figures 10A,B; Supplementary Table S1). Complete consumption of glucose before that of xylose suggests that glucose was still the preferred sugar of the engineered Synechocystis strains.

We believe that there is scope to further improve the ability of the strains to utilize xylose. Codon optimization has been previously shown to improve the expression of heterologous genes in Synechocystis (Lindberg et al., 2010; Angermayr et al., 2014; Xue et al., 2014b). Another element that is correlated with the expression level of genes is RBS (Ma et al., 2002). The strength of RBSs can be predicted and improved with the aid of a predictive design tool (Salis et al., 2009). With the help of more powerful RBSs, it will be possible to truly harvest the potential of the $x y l A B$ and $x y l F G H$ genes employed in the present and in another recent study (Lee et al., 2015). Approaches such as exploration of genomes of bacteria and algae for potential sugar transporter-catabolic genes, expression of multiple heterologous transporter genes and laboratory evolution could also prove beneficial for obtaining more efficient xyloseutilizing strains.

The strains generated in this work, especially X-Ut1 and X-Ut3, can be used directly or modified further. Introducing the $x y l A B$ genes into a glycogen synthesis gene $\operatorname{glg} C(\operatorname{slr} 1176)$ knockout enhanced the production of keto acids, and half of the carbon in the keto acids could be traced to catabolized xylose (Lee et al., 2015). An excess of carbon resulting from the absence of a carbon sink and reduced nutrient availability has been demonstrated to trigger metabolic outflow (Carrieri et al., 2012; Lee et al., 2015). Efficient xylose utilization by engineered Synechocystis strains, in addition to the aforementioned strategies, would increase the amount of carbon available for biotechnological conversion. The work reported here represents an important step toward engineering a Synechocystis strain that is able to harvest carbon from the second most abundant sugar source in nature and use it to biosynthesize a range of useful compounds.

\section{AUTHOR CONTRIBUTIONS}

SR and QH conceived the research. SR, YZ, MK, and WM designed and performed the experiments. SR analysed the data. SR and QH prepared the manuscript. All the authors have read and approved of the manuscript. 


\section{FUNDING}

The work was supported by National Science Foundation Grant MCB1120153 and Arkansas P3 Center Pilot Seed Grant P3-203.

\section{ACKNOWLEDGMENTS}

We thank the United States Department of Agriculture's Agricultural Research Service for E. coli K-12 and Z. mobilis ZM4

\section{REFERENCES}

Anderson, S., and McIntosh, L. (1991). Light-activated heterotrophic growth of the cyanobacterium Synechocystis sp. Strain PCC 6803: a blue-light requiring process. J. Bacteriol. 173, 2761-2767.

Angermayr, S. A., van der Woude, A. D., Correddu, D., Vreugdenhil, A., Verrone, V., and Hellingwerf, K. J. (2014). Exploring metabolic engineering design principles for the photosynthetic production of lactic acid by Synechocystis sp. PCC 6803. Biotechnol. Biofuels 7:99. doi: 10.1186/1754-68 34-7-99

Anwar, Z., Gulfraz, M., and Irshad, M. (2014). Agro-industrial lignocellulosic biomass a key to unlock the future bio-energy: a brief review. J. Radiat. Res. Appl. Sci. 7, 163-173. doi: 10.1016/j.jrras.2014.02.003

Baldwin, S. A., and Henderson, P. J. F. (1989). Homologies between sugar transporters from eukaryotes and prokaryotes. Annu. Rev. Physiol. 51, 459-471. doi: 10.1146/annurev.ph.51.030189.002331

Carrieri, D., Paddock, T., Maness, P. C., Seibert, M., and Yu, J. (2012). Photocatalytic conversion of carbon dioxide to organic acids by a recombinant cyanobacterium incapable of glycogen storage. Energy Environ. Sci. 5, 94579461. doi: 10.1039/C2EE23181F

Chen, T., Zhang, J., Liang, L., Yang, R., and Lin, Z. (2009). An in vivo, label-free quick assay for xylose transport in Escherichia coli. Anal. Biochem. 390, 63-67. doi: 10.1016/j.ab.2009.03.048

Davies, F. K., Work, V. H., Beliaev, A. S., and Posewitz, M. C. (2014). Engineering limonene and bisabolene production in wild type and a glycogen-deficient mutant of Synechococcus sp. PCC 7002. Front. Bioeng. Biotechnol. 2:21. doi: 10.3389/fbioe.2014.00021

Doelle, H. W. (1975). "Carbohydrate metabolism," in Bacterial Metabolism, 2nd Edn (New York, NY: Academic Press Inc), 208-312.

Eiler, A. (2006). Evidence for the ubiquity of mixotrophic bacteria in the upper ocean: implications and consequences. Appl. Environ. Microbiol. 72, 7431-7437. doi: 10.1128/AEM.01559-06

Gìrio, F. M., Fonseca, C., Carvalheiro, F., Duarte, L. C., Marques, S., and Bogel-Lukasik, R. (2010). Hemicelluloses for fuel ethanol: a review. Bioresour. Technol. 101, 4775-4800. doi: 10.1016/j.biortech.2010. 01.088

Jojima, T., Omumasaba, C. A., Inui, M., and Yukawa, H. L. (2010). Sugar transporters in efficient utilization of mixed sugar substrates: current knowledge and outlook. Appl. Microbiol. Biotechnol. 85, 471-480. doi: 10.1007/s00253-00 9-2292-1

Kawaguchi, H., Vertés, A. A., Okino, S., Inui, M., and Yukawa, H. (2006). Engineering of a xylose metabolic pathway in Corynebacterium glutamicum. Appl. Environ. Microbiol. 72, 3418-3428. doi: 10.1128/AEM.72.5.34183428.2006

Kumar, P., Barrett, D. M., Delwiche, M. J., and Stroeve, P. (2009). Methods for pretreatment of lignocellulosic biomass for efficient hydrolysis and biofuel production. Ind. Eng. Chem. Res. 48, 3713-3729. doi: 10.1021/ie801542g

Kunert, A., Hagemann, M., and Erdmann, N. (2000). Construction of promoter probe vectors for Synechocystis sp. PCC 6803 using the light-emitting reporter systems Gfp and LuxAB. J. Microbiol. Methods 41, 185-194. doi: 10.1016/S01677012(00)00162-7

Lawlis, V. B., Dennis, M. S., Chen, E. Y., Smith, D. H., and Henner, D. J. (1984). Cloning and sequencing of the xylose isomerase and xylulose kinase genes of Escherichia coli. Appl. Environ. Microbiol. 47, 15-21. strains, Dr. Qiang Wang for anti-XylA and anti-XylB antibodies, and Dr. Nawab Ali for his help with the ${ }^{14} \mathrm{C}$-labeled D-xylose uptake assay.

\section{SUPPLEMENTARY MATERIAL}

The Supplementary Material for this article can be found online at: http://journal.frontiersin.org/article/10.3389/fmicb. 2015.01484

Lee, R. A., and Lavoie, J. M. (2013). From first to third generation biofuels: Challenges of producing a commodity from a biomass of increasing complexity. Anim. Front. 3, 6-11. doi: 10.2527/af.2013-0010

Lee, T. C., Xiong, W., Paddock, T., Carrieri, D., Chang, I. F., Chiu, H. F., et al. (2015). Engineered xylose utilization enhances bio-products productivity in the cyanobacterium Synechocystis sp. PCC 6803. Metab. Eng. 30, 179-189. doi: 10.1016/j.ymben.2015.06.002

Lindberg, P., Park, S., and Melis, A. (2010). Engineering a platform for photosynthetic isoprene production in cyanobacteria, using Synechocystis as the model organism. Metab. Eng. 12, 70-79. doi: 10.1016/j.ymben.2009. 10.001

Lu, X. (2010). A perspective: photosynthetic production of fatty acid-based biofuels in genetically engineered cyanobacteria. Biotechnol. Adv. 28, 742-746. doi: 10.1016/j.biotechadv.2010.05.021

Ma, J., Campbell, A., and Karlin, S. (2002). Correlations between Shine-Dalgarno sequences and gene features such as predicted expression levels and operon structures. J. Bacteriol. 184, 5733-5745. doi: 10.1128/JB.184.20.5733-5745.2002

Malherbe, S., and Cloete, T. E. (2002). Lignocellulose biodegradation: fundamentals and applications. Rev. Environ. Sci. Biotechnol. 1, 105-114. doi: 10.1023/A:1020858910646

Marger, M. D., and Saier, Jr. M. H. (1993). A major superfamily of transmembrane facilitators that catalyse uniport, symport and antiport. Trends Biochem. Sci. 18, 13-20. doi: 10.1016/0968-0004(93)90081-W

Matsushika, A., Inoue, H., Kodaki, T., and Sawayama, S. (2009). Ethanol production from xylose in engineered Saccharomyces cerevisiae strain: current state and prospectives. Appl. Microbiol. Biotechnol. 84, 37-53. doi: 10.1007/s00253-009-2101-x

McEwen, J. T., Machado, I. M. P., Connor, M. R., and Atsumi, S. (2013). Engineering Synechococcus elongates PCC 7942 for continuous growth under diurnal conditions. Appl. Environ. Microbiol. 79, 1668-1675. doi: 10.1128/AEM.03326-12

Meijnen, J. P., de Winde, J. H., and Ruijssenaars, H. J. (2008). Engineering Pseudomonas putida S12 for efficient utilization of D-xylose and L-arabinose. Appl. Environ. Microbiol. 74, 5031-5037. doi: 10.1128/AEM. 00924-08

Mohamed, A., and Jansson, C. (1989). Influence of light on accumulation of photosynthesis-specific transcripts in the cyanobacterium Synechocystis 6803. Plant Mol. Biol. 13, 693-700. doi: 10.1007/BF00016024

Munyon, W. H., and Merchant, D. J. (1959). The relation between glucose utilization, lactic acid production and utilization and the growth cycle of L strain fibroblasts. Exp. Cell Res. 17, 490-498. doi: 10.1016/0014-4827(59) 90069-2

Niederholtmeyer, H., Wolfstadter, B. T., Savage, D. F., Silver, P. A., and Way, J. C. (2010). Engineering cyanobacteria to synthesize and export hydrophilic products. Appl. Environ. Microbiol. 76, 3462-3466. doi: 10.1128/AEM. 00202-10

Pothiraj, C., Kanmani, P., and Balaji, P. (2006). Bioconversion of lignocellulose materials. Mycobiology 34, 159-165. doi: 10.4489/MYCO.2006.34.4.159

Prentki, P., and Krisch, H. M. (1984). In vitro insertional mutagenesis with a selectable DNA fragment. Gene 29, 303-313. doi: 10.1016/0378-1119(84) 90059-3

Ragauskas, A. J., Williams, C. K., Davison, B. H., Britovsek, G., Cairney, J., Eckert, C. A., et al. (2006). The path forward for biofuels and biomaterials. Science 311, 484-489. doi: 10.1126/science.1114736 
Ren, C., Chen, T., Zhang, J., Liang, L., and Lin, Z. (2009). An evolved xylose transporter from Zymomonas mobilis enhances sugar transport in Escherichia coli. Microb. Cell Fact. 8:66. doi: 10.1186/1475-2859-8-66

Saier, M. H. Jr., and Crasnier, M. (1996). Inducer exclusion and the regulation of sugar transport. Res. Microbiol. 147, 482-489. doi: 10.1016/S09232508(96)90150-3

Salis, H. M., Mirsky, E. A., and Voigt, C. A. (2009). Automated design of synthetic ribosome binding sites to control protein expression. Nat. Biotechnol. 27, 946-950. doi: 10.1038/nbt.1568

Schellenberg, G. D., Sarthy, A., Larson, A. E., Backer, M. P., Crabb, J. W., Lidstrom, M., et al. (1984). Xylose isomerase from Escherichia coli. Characterization of the protein and the structural gene. J. Biol. Chem. 259, 6826-6832.

Vieira, J., and Messing, J. (1982). The pUC plasmids, an M13mp7-derived system for insertion mutagenesis and sequencing with synthetic universal primers. Gene 19, 259-268. doi: 10.1016/0378-1119(82)90015-4

Vinuselvi, P., Kim, M. K., Lee, S. K., and Ghim, C. M. (2012). Rewiring carbon catabolite repression for microbial cell factory. BMB Rep. 45, 59-70. doi: 10.5483/BMBRep.2012.45.2.59

Weisser, P., Krämer, R., Sahm, H., and Sprenger, G. A. (1995). Functional expression of the glucose transporter of Zymomonas mobilis leads to restoration of glucose and fructose uptake in Escherichia coli mutants and provides evidence for its facilitator action. J. Bacteriol. 177, 3351-3354.

Xiong, X., Wang, X., and Chen, S. (2012). Engineering of xylose metabolic pathway in Rhodococcus strains. Appl. Environ. Microbiol. 78, 5483-5491. doi: 10.1128/AEM.08022-11

Xue, Y., Zhang, Y., Cheng, D., Daddy, S., and He, Q. (2014a). Genetically engineering Synechocystis sp. Pasteur Culture Collection 6803 for the sustainable production of the plant secondary metabolite p-coumaric acid. Proc. Natl. Acad. Sci. U.S.A. 111, 9449-9454. doi: 10.1073/pnas.13237 25111
Xue, Y., Zhang, Y., Grace, S., and He, Q. (2014b). Functional expression of an Arabidopsis p450 enzyme, p-coumarate-3-hydroxylase, in the cyanobacterium Synechocystis PCC 6803 for the biosynthesis of caffeic acid. J. Appl. Phycol. 26, 219-226. doi: 10.1007/s10811-013-0113-5

Yao, L., Qi, F., Tan, X., and Lu, X. (2014). Improved production of fatty alcohols in cyanobacteria by metabolic engineering. Biotechnol. Biofuels 7:94. doi: 10.1186/1754-6834-7-94

Young, E., Lee, S. M., and Alper, H. (2010). Optimizing pentose utilization in yeast: the need for novel tools and approaches. Biotechnol. Biofuels 3:24. doi: 10.1186/1754-6834-3-24

Zhang, C. C., Durand, M. C., Jeanjean, R., and Joset, F. (1989). Molecular and genetical analysis of the fructose-glucose transport sy stem in the cyanobacterium Synechocystis PCC 6803. Mol. Microbiol. 3, 1221-1229. doi: 10.1111/j.1365-2958.1989.tb00272.x

Zhang, M., Eddy, C., Deanda, K., Finkelstein, M., and Picataggio, S. (1995). Metabolic engineering of a pentose metabolism pathway in ethanologenic Zymomonas mobilis. Science 267, 240-243. doi: 10.1126/science.267.5195.240

Zhou, J., Zhang, H., Meng, H., Zhu, Y., Bao, G., Zhang, Y., et al. (2014). Discovery of a super-strong promoter enables efficient production of heterologous proteins in cyanobacteria. Sci. Rep. 4:4500. doi: 10.1038/srep04500

Conflict of Interest Statement: The authors declare that the research was conducted in the absence of any commercial or financial relationships that could be construed as a potential conflict of interest.

Copyright (c) 2015 Ranade, Zhang, Kaplan, Majeed and He. This is an open-access article distributed under the terms of the Creative Commons Attribution License (CC BY). The use, distribution or reproduction in other forums is permitted, provided the original author(s) or licensor are credited and that the original publication in this journal is cited, in accordance with accepted academic practice. No use, distribution or reproduction is permitted which does not comply with these terms. 